\title{
El sentido de la muerte y la crueldad durante la Primera Guerra Mundial
}

Wilson R. Pabón Q.'

Universidad Autónoma de Colombia

Artículo de Reflexión derivado de investigación Recibido: 26-09-2014 Aprobado: 21-II-2014

\section{Resumen}

Durante la Primera Guerra Mundial se utilizaron adelantos tecnológicos que se destinaron al servicio de la muerte. Quienes hicieron parte de los enfrentamientos soñaban con una guerra romántica, pero se encontraron con la muerte industrializada, que no distinguía amigos ni enemigos. El presente estudio pretende analizar la forma en que quienes participaron en ella verían el morir y entenderían la crueldad. A partir del análisis de testimonios de la época, con las herramientas de análisis propuestas por varios estudiosos, se intentará comprender cómo la guerra y la muerte cambiaron las percepciones de la vida y la muerte alrededor de la guerra.

Palabras clave: Primera Guerra Mundial, muerte, crueldad, neurosis de guerra, violencia expresiva, consentimiento asesino, testigo, testimonio.

l Historiador de la Universidad Nacional de Colombia. Magister en Ciencias Sociales de las Religiones y candidato a Doctor en Antropología Histórica de la École Pratique des Hautes Études - Sorbonne (París). Miembro de la Junta Directiva de la Asociación Colombiana de Historiadores. Docente cátedra indefinido de la carrera de historia, Facultad de Ciencias Humanas, Fundación Universidad Autónoma de Colombia. Dirección electrónica: wilsonpq@hotmail.com 


\title{
The sense of death and the cruelty during the First World War
}

\begin{abstract}
During the First World War it was used advanced technologies, which were designated to the service of death. Those who were part of confrontations dreamt about a romantic war, but they found an industrialized war, which did not differentiate either friends or enemies. The pretension is to analyse the way in which those who participate in it would see the dying process and would understand the cruelty in a different way. From this analysis of testimonies of the epoch, with the tools of the study proposed by several scholars, it will be proved how war and death changed the perception of life and interpersonal relationships for the 20th century.
\end{abstract}

Key words: First World War, death, cruelty, expressive violence, testimony, the art of war.

\section{O sentido da morte e a crueldade durante a Primeira Guerra Mundial}

\section{Resumo}

Durante a Primeira Guerra Mundial foram utilizados avanços tecnológicos que se destinaram ao serviço da morte. Aqueles que participaram dos enfrentamentos sonhavam com uma guerra romântica, mas se encontraram com a morte industrializada, que não diferenciava amigos nem inimigos. Pretende-se analisar a forma em que aqueles que participaram dela veriam o morrer e entenderiam a crueldade de uma maneira diferente. Partindo da análise das testemunhas da época, com as ferramentas analíticas propostas por vários estudiosos, vai se demonstrar como a guerra e a morte mudaram as percepções da vida e as relações interpessoais para o século XX.

Palavras chave: Primeira Guerra Mundial, Morte, Crueldade, Violência expressiva, Testemunha, Arte da guerra.

"Los hombres mueren realmente; y ya no individuo por individuo, sino multitudes de ellos, a menudo decenas de miles un solo día".

Sigmund Freud $(1915)^{2}$

\section{Introducción}

La Primera Guerra Mundial marcó el inicio del siglo XX en todas sus dimensiones. Fue el gran corolario del pensamiento occidental en la búsqueda del desarrollo, y todas las ideas generadas durante el siglo

2 Sigmund Freud. "De guerra y muerte: temas de actualidad", en: Obras Completas. Buenos Aires: Amorrortu Editores, Tomo XIV, 1993, págs. 290-292. 
XIX vieron sus frutos en los aciagos años del conflicto. No obstante, el encuentro del hombre con la modernidad fue llevado a través de la muerte; se llegó a pensar que la única manera de definir el futuro de las naciones sería mediante las armas, inclusive acabar con los enfrentamientos entre naciones solo lo permitiría una guerra definitiva a gran escala. Con ésta, aparentemente, se acabarían todas las guerras.

Pero no solo se debe entender este periodo como el de la guerra en cifras de inversión, heridos y muertos; el ver de frente la muerte para muchos, quienes no sabían a qué se enfrentaban, terminó por convertir a este conflicto, en uno de los más sangrientos de la historia, y peor aún, en la antesala de uno inclusive más triste y desolador: la Segunda Guerra Mundial.

Desde jóvenes ansiosos hasta ancianos temerarios hicieron filas interminables para enlistarse en los ejércitos nacionales, para defender los símbolos e ideales de sus estados-nación. Muchos falsificaron papeles para ser más viejos o menores, otros veían en la guerra la única forma de escalar en las jerarquías sociales, y algunos se habían dejado llevar por la propaganda política nacionalista que les mostraba la guerra de la forma romántica en que la contaban los militares decimonónicos. Sin embargo, la muerte y la crueldad enfermaron las mentes y los corazones de quienes llegaban deseosos de matar alemanes o franceses, turcos o ingleses, rusos o austrohúngaros; los muertos eran reales y la sangre no era solo roja sino espesa, y brotaba a borbotones de los cuerpos de los combatientes. Familiares y amigos fueron cayendo a lado y lado de quienes contarían los horrores de la guerra; ya que, con la industrialización puesta al servicio de la muerte, las balas ya no distinguirían entre amigos y enemigos, ni las bombas y los óbuses que ahora eran tan impersonales que ni siquiera la población civil se salvó de los tentáculos de la destrucción.

Aquellos que relataron los hechos de la Primera Guerra ya no eran los mismos que partieron orgullosos con sus uniformes impecables y coloridos; regresaron mutilados, con problemas mentales y con traumas de guerra, trataron de rehacer sus vidas, otros tantos quedaron como simples cifras en una guerra en la que los muertos se contaron por millones -algunos hablan de 13 otros de 20-, y en la que, durante las campañas, las apuestas vencedoras se medían en altos porcentajes de pérdidas, terminando, muchas veces, con simples victorias pírricas que no definieron el curso del conflicto.

La muerte ya no se vio igual, y en las guerras - principalmente en ésta- la crueldad pasó a ser cotidiana durante más de cuatro años. Al enemigo había que eliminarlo a toda costa; y aquí el soldado fue víctima y victimario a la vez. No obstante, los muertos son reales y las vidas de quienes la padecieron ya no fueron las mismas.

\section{La muerte en el cine sobre la Primera Guerra Mundial}

En 1957 se proyecta la película Paths of Glory de Stanley Kubrick (traducida al castellano como Senderos de Gloria en Hispanoamérica y Patrulla Infernal en España). Excelente film abiertamente antibelicista, que recrea la Primera Guerra a través de un batallón de infantería francés, comandado por el coronel Dax (Kirk Douglas), que tiene como tarea la toma de El Hormiguero, un inexpugnable bastión alemán 
sobre una colina. La acción resulta convirtiéndose en un verdadero infierno, los muertos y heridos son incontables, y la compañía decide regresar a su trinchera. El alto mando militar toma esto como un acto de cobardía, por lo cual decide fusilar a tres soldados escogidos al azar, en sustitución de todo el grupo, ya que sería muy costoso llevarlos a todos a la muerte por las armas de sus compatriotas.

Su antibelicismo, y el hecho de tomar como referencia el ejército francés, además de incluir La Marsellesa en la banda sonora con algunos cambios, hizo que la película fuera rechazada en Francia, por lo que debió ser filmada en Alemania, y estrenada en los cines parisinos solamente hasta 1975.

Kubrick se basó en la novela del mismo nombre, escrita por Humphrey Cobb en 1915, quien, a su vez, tomó como referencia un hecho real de fusilamiento de cuatro soldados franceses por insubordinación. Y, si bien es una recreación, presenta de una forma magnífica la vida en las trincheras, lo mismo que la lógica militar nacionalista y xenófoba, y, para lo que nos compete en el presente escrito, el sentido de la muerte y la crueldad durante los años de la Gran Guerra.

Para esto último, nos centraremos en analizar un fragmento de este filme, en el que dos soldados franceses discuten alrededor de la manera en que prefieren morir. Transcribimos a continuación:

- No tengo miedo de morir mañana. Sólo de que me maten.

- Eso no tiene sentido.

- ¿Con qué quisieras que te maten?, ¿con bayoneta o ametralladora?

- Es obvio que con ametralladora.

- Lo mismo digo. Las dos son piezas de acero que te penetran las tripas. Pero la ametralladora es más rápida y menos dolorosa.

- ¿Y eso que prueba?

- Que la mayoría de nosotros tiene más miedo de que lo hieran que de que lo maten. Bernard, por ejemplo, le da pánico el gas. A mí el gas no me molesta. Ha visto fotos de gente envenenada por el gas, pero a mí no me afecta. ¿Pero sabes qué? No podría estar sin mi casco de hierro. Pero no me importa tener uno en el trasero. ¿Sabes por qué?

- El cerebro está en la cabeza.

- Porque una herida en la cabeza duele más que una en el trasero. El trasero es pura carne, pero la cabeza es puro hueso.

- Habla por ti no más.

- Dime algo. Sin contar las bayonetas, ia qué le tienes más miedo?

- A los altos explosivos.

- Exacto. A mí me pasa lo mismo. Porque sé que pueden destriparte de la peor forma posible. Es así como te digo. Si de veras tienes miedo de morir, vivirás con 
pánico toda tu vida, porque sabes que algún día, deberás partir. Si sólo temes la muerte, ¿por qué te importa la forma de morir?

- Muy complicado, profesor. Lo único que sé es que nadie quiere morir.

Curioso diálogo que muestra la realidad de la guerra. Igualmente, una manera de saber que, en realidad, los soldados de la Primera Guerra Mundial se preocupaban por la forma en que iban a morir la encontraremos en los diarios y las cartas que escribieron en el frente de batalla. Sin embargo, esta conversación recreada dejar ver crudamente el miedo a la muerte, pero no cualquiera, aquella dolorosa y deformante, la que se puede dar de múltiples formas, la que se vivió por estos años, es decir, la muerte moderna.

De la misma forma, estas películas basadas en las guerras, y principalmente las pocas hechas sobre la Primera, tienen o deben tener un componente macabro o triste que le muestre al espectador lo desgarradora que puede llegar a ser la muerte. "Adiós a las armas", "Sin novedad en el frente", "Galípoli", "Feliz Navidad", inclusive "Caballo de Guerra", entre otras, nos dan luces al respecto.

El miedo al morir lo manifiestan en sus rostros los actores que recrean estos años dolorosos, con escenas que llegaron inclusive a ser consideradas como clásicas. La muerte segura llegará, pero no se sabe cómo: ametralladoras, bombas, minas antipersonales, bayonetas, etc., hacen parte del nuevo repertorio de la guerra, algo que muchos no se imaginaban, y para lo que fueron utilizados los avances tecnológicos de la época: la celeridad y masificación de la muerte. Además, esta fue una de tantas herencias macabras que dejó la Primera Guerra Mundial para los conflictos posteriores y presentes alrededor del mundo.

\section{Los relatos de los combatientes de la Gran Guerra}

Para poder entender, de la misma manera, el sentido de la muerte y la crueldad entre 1914 y 1918 , nos basaremos en los relatos de los combatientes que consignaron sus experiencias en diarios personales, en su correspondencia a familiares y amigos, o que llegaron incluso a escribir novelas donde son protagonistas. Algunos de estos documentos se encuentran principalmente en la sección de manuscritos y de libros raros y curiosos de la Biblioteca Luis Ángel Arango, de la ciudad de Bogotá, ya que, por ser de la época de la Gran Guerra, tienen una conservación particular.

Comenzaremos entonces con Paul Tuffrau, hombre de letras, escritor y profesor, quien en 19/4 parte a la guerra a defender los intereses franceses como subteniente (hay que recordar que, para la época, los profesionales fueron reclutados como oficiales de bajo y medio rango), fue herido varias veces durante los 4 años de guerra pero siguió combatiendo, lo que hizo que recibiera la Cruz de la Guerra con la cara vendada y terminara siendo nombrado como comandante en jefe de batallón $n^{3}$.

3 Paul Courteault. "Un conteur de guerre bordelais", en: Revue Philomathique de Bordeaux et du Sud-Ouest. 20e année, No. 6, novembre-décembre 1917, pág. 257. 
Durante la guerra consignó sus experiencias en las trincheras y en los combates en su diario personal, luego las enviaba por correo al periódico Le Journal bajo el seudónimo de Teniente E. R., rotativo que las publicó regularmente; finalmente, para el año de 1917, se recopilaron y le fue impreso un texto con el nombre de Carnet d'un combattant. Ya en 1998, luego de su muerte, se reeditó con el título: 1914-1918 - Quatre Années sur le Front. Carnets d'un Combattant, texto que todavía no cuenta con traducción al español.

En sus relatos se puede evidenciar que, a menudo, muchas órdenes provenientes de los estados mayores no se adaptaban a las realidades que se vivían en el campo de batalla, los generales no conocían el terreno, para ellos muchas veces la guerra funcionaba como un juego de estrategia en el que los generales, asentados en castillos y cuarteles, simplemente movían fichas de colores sobre un mapa pegado a la pared o puesto sobre una mesa.

Lo más importante de los relatos de Tuffrau no es solamente que pertenecen a un hombre que participó plenamente en los combates y en la vida en la Gran Guerra durante los cuatro años de conflicto, y que además sobrevivió para contarlo (murió en 1973), sino que, igualmente, sus relatos narran con extremo humanismo las dificultades y tristezas de este conflicto. Pasa de trinchera en trinchera narrando cómo las balas, las granadas y los obuses explotaban alrededor de todos, pero también, cuando todo se calmaba, nos hace ver y pensar en la belleza de los paisajes, en la dulzura de la primavera o en el encanto de los pueblos por los que atravesó.

Varios de sus relatos son presentados a la manera de diálogo con sus compañeros de trinchera, en uno de ellos, con un soldado de apellido Cordier, discuten alrededor de su vida en el frente de batalla en comparación con la de aquellos que permanecieron viviendo tranquilos en las ciudades. Tuffrau es insistente en indicarle a Cordier que su función es la de ayudar a mantener a Francia a salvo, que el hecho de que en las ciudades se viva en calma, no es por culpa de los civiles, sino que eso hace parte del vivir en tiempos de guerra; en el frente se deben olvidar las tentaciones, aquellas que disfrutan quienes no están en las trincheras, y por eso es que tanto ellos como los combatientes tienen que durar, a lo que el soldado contesta:

"-iAy! Ellos durarán, mi teniente, no se preocupe... Y si esto sigue así, se acostumbrarán muy bien de vernos en las trincheras.

-Todavía no hemos llegado allí, Cordier. Todas las familias que tienen miembros en el frente desean fuertemente su preservación y su regreso.

-Sí, ipero también hay quienes no tienen a nadie? O quienes sólo tienen a alguien en las intendencias, en la administración, en los suministros, en los parques, en los convoyes, en las oficinas, en los servicios, en todos esos sitios amueblados donde se tienen cinco por ciento de posibilidades de morir en el campo de honor, mientras que nosotros, ostentamos el noventa y cinco... Aquellos esperarán; vivirán normalmente, como usted lo dice; ellos pensarán salvarse con un poco de dinero donado a la Cruz Roja. Y nosotros, ipor Dios! damos nuestro tiempo, nuestra piel, nuestra 
felicidad; vivimos en el barro, bajo la constante amenaza del valle a atravesar, del obús que explota, de la mina que estalla, de la bocanada de cloro que nos hará escupir nuestros pulmones. ¡Eso no se equipara en nada! Y no hay que creer que después de la guerra, las dos partes se la llevará bien. Eso no."

Este aparte nos muestra no sólo la dificultad de vivir dentro de la guerra, sino también los cuestionamientos que comienzan a hacerse aquellos que la viven en carne propia. El miedo a la muerte es latente, vivo, constante. El soldado se preocupa de cómo va a morir, pero también de porqué tiene que hacerlo mientras otros siguen en sus vidas felices y tranquilas. Esto fue lo que generó desidia y odio a la muerte.

Siguiendo con los testimonios, Tuffrau nos cuenta lo difícil que era atravesar la "tierra de nadie", la zona de muerte en la que millares perdieron la vida, sobre todo en los días del invierno, tan sombríos y tristes, y en los cuales hasta los huesos duelen y la muerte acecha:

"Fuera, con los pies completamente enterrados, sacudo trozos de barro glacial que me pesan en las manos... Retomo mi marcha, las piernas abiertas, atravesando la tierra blanda de los desprendimientos, sondeando prudentemente el fango que tapa los hoyos. Y, pese a todo, a veces, el sitio hacia el que he lanzado mi impulso se hunde, el barro aspira mi pierna, la agarra, la paraliza; debo hacer un gran esfuerzo para liberarla. Del fondo del agujero que se ha llenado en seguida de agua, mi pie saca un lío de cables en el que reconozco una línea telefónica. Justamente ahí aparece el telefonista encargado de reparar las líneas, trae la cara contraída por las agujas heladas de la lluvia: '¡Vaya desorden! ¡No se ha conservado nada ahí dentro! ¡Sólo hay barro y cadáveres!'. Sí, cadáveres. Los muertos en los combates de otoño, que habían sido enterrados someramente en el parapeto, aparecen a trozos en los desprendimientos de tierra" ${ }^{\prime \prime}$

Aquí se evidencia lo difícil que era vivir entre el barro, las ratas, los cables telefónicos, las bombas y los obuses que explotaban por doquier, muertos y heridos, la sangre mezclada con el gris de la suciedad y la muerte, y cadáveres... cuerpos inertes de aquellos que no conocíamos y que fueron nuestros amigos en los últimos meses o años. Pero la pregunta que se hacían todos aquellos que hicieron parte de la Gran Guerra era: ¿cómo vamos a morir?

Otros textos francófonos que nos cuentan estos aciagos años son: Au pays de la mort ${ }^{6}$ de Benjamin Vallotton, Souvenirs de Guerre ${ }^{7}$ de Alain, Les violences allemandes a l'econtre des non-combattants ${ }^{8}$ de

4 Paul Tuffrau (Lieutenant E. R.). Carnet d'un combattant. París: Payot, 1917, pág. 154. [Traducción del autor].

5 Paul Tuffrau. Op. Cit., pág. 15.

6 Benjamin Vallotton. Au pays de la mort. París: Neuchatel Atttinger Fréres Editeurs, [s. f.].

7 Alain. Souvenirs de guerre. París: Paul Hartmann Éditeur, 1937.

8 Antoine Pillet. Les violences allemandes a l'econtre des non-combattants. París: Recueil Sirey, 1917. 
Antoine Pillet, Bélgica mártir ${ }^{9}$ de Pierre Nothomb, o inclusive el informe de la Comisión Investigadora de los Atentados Atribuidos a los alemanes ${ }^{10}$. Textos producidos en los mismos años de la guerra y que tampoco cuentan todavía con traducciones al castellano.

En su mayoría tratan de analizar la muerte y la crueldad pero desde el lado de los aliados, trataremos, ahora, de analizar una mirada del otro lado de las trincheras.

\section{El miedo a la muerte en los alemanes}

Para poder entender las manifestaciones de miedo a la muerte y del sentido de la crueldad por los años de la guerra, ahora en el bando contrario, el de las potencias centrales, nos centraremos en entender algunas referencias descritas por un militar alemán de nombre Edlef Köppen (I 893-1939).

El caso de este personaje es bien representativo de las características que tuvo el conflicto, y de las consecuencias que éste tuvo sobre quienes lo vivieron, lo mismo que para la nación alemana en su conjunto. Köppen para los años del comienzo de la guerra era un estudiante de Filosofía y Letras que, apropiándose del discurso del nacionalismo que inundó a Europa e impregnó a sus habitantes, se enlistó en el ejército para defender el discurso de la raza superiora noreuropea.

Se destacó como artillero en el frente occidental, pero, en 1916 durante la batalla del Somme, en Francia, fue herido de gravedad. Lo vivido durante la guerra y su difícil recuperación hicieron que sintiera una ascendente repulsión hacia la guerra, lo que generó que, hacia finales de la misma, fuera declarado enfermo mental y encerrado en un hospital psiquiátrico militar. Luego de la guerra, trató de terminar sus estudios sin lograr su cometido, y se dedicó a la reportería y a la radio" ".

Sus traumas de guerra le permitieron sentarse a escribir su principal obra, traducida a varios idiomas, inclusive al español, debido a su importancia como testimonio de este conflicto. El texto lo tituló Parte de Guerra, y gira alrededor de un personaje ficticio, el artillero Reisiger, quien al comienzo del relato es un entusiasmado combatiente que, por sus heróicas acciones se convierte en alférez, pero quien, con el paso del tiempo se va desencantando de la guerra hasta que se niega a seguir en la lucha junto a sus compañeros. Tan importante escrito lo aprovecharemos para continuar con nuestras reflexiones.

Al grito de ¡Viva la Muerte!, los oficiales animaban a sus combatientes para la lucha contra el enemigo. La vida de aquellos del bando contrario se minimizaba sobre mapas, ya que, como lo relata Köppen, un círculo de tinta rojo marcaba la lluvia de proyectiles del gas y un cuadrado negro

$9 \quad$ Pierre Nothomb. Bélgica mártir. París: Parrin, 1915.

10 Comisión Investigadora de los Atentados Atribuidos a los alemanes. Informe acerca de los atentados atribuidos a los alemanes. Londres: Thomas Nelson, 1915.

II Las referencias biográficas alrededor de la vida de Eddlef Köppen son muy cortas en español, por lo que tuvimos que referirnos a una reconstrucción con base en su texto traducido, lo mismo que algunas páginas de internet en francés y alemán al respecto. 
una tormenta de metralla de obuses ${ }^{12}$; milímetros dentro de la cartografía significaba la muerte de cientos o de miles.

El sentido de la muerte se comienza a desvanecer conforme van pasando los días, al igual que con los innumerables combates que sufren los soldados, hasta el punto de no importar cómo ésta va a llegar. En un apartado, el autor cuenta que el alférez Reisiger sufre de disentería, el médico de la compañía lo incita a quedarse en la trinchera y no ir a combatir, ya que podría tener una recaída, a lo que él simplemente contesta: "Morir de un tiro o de cagalera, querido doctor... qué más da."'13

En otro momento, Reisiger se encuentra con un oficial, en una trinchera alemana que acaba de ser bombardeada y atacada por los aliados, y le pregunta sobre lo sucedido, la respuesta del comandante es casi nula, de estupefacción, una risa macabra que resulta siendo un tremendo llanto convulsivo, y lo único que atina a hacer es mostrarle al alférez con la mirada lo sucedido:

"Ni una palabra más. Sobre el parapeto, la rodilla sobre una escala de asalto, yace un soldado de infantería con la cara blanca. $Y$ a su lado, otro. $Y$ un tercero. $Y$ un cuarto. $Y$ un quinto. $Y$ diez. $Y$ cien. Hasta el horizonte: un hombre junto a otro. La cabeza siempre bastante alta, la mano en el fusil. La rodilla izquierda siempre encima del último peldaño de la pequeña y desvencijada escala de asalto. Y siempre un pequeño agujero debajo del casco de acero. En el entrecejo, en la mejilla, al lado del oído, o en el cuello."'4

La escena continúa con una caminata al interior de la trinchera, donde se encuentran una pierna enganchada en una escalera o un pie suelto dentro de una bota mugrienta. El escenario es la guerra, la muerte en todo su esplendor, y el llanto del comandante manifiesta el dolor y el miedo. Esto marcará a Reisiger, y la guerra ya no la verá como antes; esto lo manifiesta con expresiones como: "Cada vez dudo más que el deber de una persona sea morir. Cada vez comprendo menos que el sentido de la vida sea la muerte, pues las personas cometemos el pecado más monstruoso contra la vida al morir de un modo tan absurdo." ${ }^{5}$ Pero lo que estaba de fondo era más complicado, no se trata de que los seres humanos encuentren la muerte de forma violenta, sino que a esta se interpone la idea del deber, el sentido de morir por la patria ${ }^{16}$ se comienza a desvanecer. La tal muerte honrosa en el campo de batalla, con la que soñaron millones, se comienza a transformar en un miedo a la misma,

12 Edlef Köppen. Parte de Guerra. Barcelona: Sajalín editores, 20 I2, pág., 402-403.

13 Edlef Köppen. Parte de Guerr. Op.Cit., pág. 4 I2.

I4 Ibídem., pág. 438.

15 Ibídem.,pág. 450.

I6 Para poder entender la idea planteada de morir por la patria, en este caso la alemana, Köppen se sirve de fragmentos de artículos, cartas o discursos. En este caso, las palabras pronunciadas por Guillermo II el 23 de noviembre de |89|, ilustran el deber de los alemanes de morir por su Kaiser: "...y puede ocurrir que tengáis que matar de un tiro o acuchillar a vuestros propios parientes y hermanos. Entonces la lealtad quedará sellada con el sacrificio de vuestra sangre... (o) en las actuales intrigas socialistas puede ocurrir que yo os ordene disparar contra vuestros parientes, hermanos, incluso padres -Dios no lo quiera-, pero incluso entonces tendréis que obedecer mis órdenes sin rechistar... (o) y si alguna vez tuviera -Dios no lo quiera- que ordenaros disparar sobre vuestros propios parientes, incluso hermanos y padres, jrecordad vuestro juramento!. Ibídem. , pág. 465. 
en un repudio a perecer de manera monstruosa en la guerra, se transforma en un deseo arrollador por vivir.

La historia de Reisiger termina igual que la de su creador, luego de los hechos antes descritos y de todas sus vivencias en el frente, decide no continuar combatiendo, por esto es hecho preso y conducido a la comandancia general para que rinda descargos por lo sucedido, en donde declara que considera que "la guerra es el mayor de todos los crímenes". Después de un proceso y una evaluación psiquiátrica, es declarado loco y encerrado en un manicomio. El texto concluye con la situación médica del heróico pero desequilibrado alférez, en la que se señala que: "Estado igual que la semana pasada. El enfermo no duerme, no come, mira fijamente al vacío. Cuando se le habla, responde siempre con la misma frase: 'Todavía hay guerra. ¡Tocadme los cojones!'."'77

La vida real del autor de este esclarecedor escrito, Edlef Köppen, es como la de su protagonista al interior del libro. Este novelista y literato, termina convirtiéndose en un pacifista y hombre de izquierda. Parte de Guerra fue publicado en 1930, pero en 1933, con la llegada del nazismo al poder en Alemania, Köppen es apartado de su cargo, y con Hitler se prohibe la publicación de su texto y su edición fue secuestrada. Las secuelas de sus vivencias durante la Gran Guerra, lo mismo que sus heridas le provocaron una muerte prematura en 1939, año del comienzo de la Segunda Guerra Mundial.

\section{Consecuencias de la crueldad durante la Primera Guerra Mundial en el arte}

El siglo $X X$ es considerado por varios investigadores como el más violento de la historia de la humanidad. Millones de muertos, ciudades destrozadas, un número de víctimas incalculable, y la tecnología destinada al servicio de la guerra. Igualmente, los tentáculos de la muerte llegaron a transformar el arte del siglo XX, así, como lo afirma el poeta argentino y crítico literario y de cine, Héctor Freire: "una de las características más significativas del arte del siglo XX y del contemporáneo es la 'crueldad'." Porque, "Ya lo decía Schopenhauer, nadie puede mandar al artista que haga una obra 'elevada', 'moral', 'noble', 'cristiana' y 'piadosa', que deje de ser esto o lo otro; porque tanto el artista como su obra es el espejo de la humanidad y presenta a ésta la imagen fiel de lo que siente."'8 Freire, continúa diciéndonos al respecto que:

"Luego de la primera guerra mundial, pintores expresionistas como Otto Dix [alemán, impulsor de la nueva objetividad], Oscar Kokoschka [austriaco] o Emil Nolde [alemán], verdaderos 'artistas del escalpelo' desplazaran el arte de la herida al del cuchillo. [...] Y después, los fundadores del dadaísmo afirmarán: la vida debe doler. O las propuestas del futurismo a favor de 'la guerra, como higiene del mundo'.

17 Ibídem. , pág. 499.

18 Héctor ]. Freire. "Arte de la crueldad", en: Revista Topia. Buenos Aires, octubre 2003. [En línea: https://www.topia.com.ar/articulos/ arte-de-la-crueldad]. 
Conocemos como siguió todo esto. Hasta la vuelta de tuerca dada por Artaud en su ya clásico 'Teatro de la Crueldad', o el mismo Kafka en su famosa y absurda 'Metamorfosis' ante la impiedad del nuevo y supuesto 'humanismo' moderno. A esta altura de la historia del arte, cabría preguntarse ¿No había suficiente muerte e impiedad, para que el arte, a su vez se transformara en una crónica de la crueldad del siglo $X X$ ?."'

Para esto también hay que entender que varios intelectuales y artistas europeos llegaron a hablar de la "crueldad sistemática", que no es simplemente excepcional. No podemos pensar que el hombre llegó a ser cruel por las condiciones de la guerra, sino que ésta es lo que Kierkegaard llamó en su Diario, "el silogismo de la crueldad", en donde llega a considerar que todo racionalismo: "ya ético, ya político, ya religioso, ya artístico, en el fondo no es sino 'crueldad organizada'."'20 Igualmente, el arte moderno, entendido como el del siglo XX, le da paso a ese ambiente, a entender que es consecuencia de estas realidades mortuorias, a la manera de la fotografía como arte.

Y para el caso de la fotografía, que transforma al retratado en una víctima del interés del fotógrafo, que a veces se aprovecha del infortunio o el dolor del otro, es necesario ver el debate de Susan Sontag en su texto Sobre la fotografia ${ }^{2 !}$.

Freire termina diciéndonos: "En síntesis, si el 'arte de la crueldad' es esencialmente humano, también lo es su libertad: la crueldad como acto creativo es el ejercicio de la libertad. [...] ¿Qué vemos en el Guernica? Vemos barbarie, muerte, monstruosidad, violencia, tragedia, guerra, crueldad. Sin embargo, Picasso no empuñó un arma. Empuñó un pincel. [... . El arma mata. El pincel inmortaliza."22 La muerte y la crueldad transformaron el arte, el mundo ya no fue el mismo y el dolor que dejaron estos años se manifestó de múltiples formas, los artistas trataron de plasmarlo en sus obras.

\section{Por una explicación de la violencia y la muerte durante la Primera Guerra Mundial}

La Gran Guerra dejó una nueva patología: la neurosis de guerra, atada al horror, el ruido de las explosiones y la muerte de camaradas de combate, que dejó víctimas en el campo de batalla y en la retaguardia. Lassa Oppenheim ( | 858-19|9), la describió como una afección orgánica consecutiva a un traumatismo real que provocaba una alteración física de los centros nerviosos, acompañada de síntomas psíquicos tales como: depresión, hipocondría, angustia, delirio, etc.

"El tratamiento de la psiquiatría militar de la época era la cura de Kaufman [tratamiento de choques eléctricos, ya que se consideraba que muchos habían simulado

\footnotetext{
19 Ibídem.

20 Ibídem.

21 Susan Sontang. Sobre la fotografía. Barcelona: Edhasa, 1996.

22 Héctor J. Freire. "Arte de la crueldad", en: Revista Topia. Buenos Aires, octubre 2003.
} 
su enfermedad], que causó la muerte de algunos pacientes. El imperativo de la guerra imponía a los médicos no la atención del sujeto, sino, en el menor tiempo posible, regresar un soldado a las trincheras. Los psicoanalistas, en cambio, se dieron a la tarea de demostrar la eficacia del psicoanálisis, tratamiento más humanitario y, no obstante, igual de eficaz, y a la de inferir su etiología, sus mecanismos, su estructura y sintomatología; es decir, hacer avanzar el psicoanálisis en sus conceptos, en su clínica y en su procedimiento investigativo."23

Sigmund Freud, quien para el comienzo de la Primera Guerra Mundial ya contaba con 58 años, se preocupó por entender el porqué de la guerra y de su tiempo; además, el "padre del psicoanálisis", intentaría explicar la muerte, la crueldad y la neurosis a partir de esta práctica terapéutica que creó desde 1896.

Para muchos intelectuales de comienzos de siglo, la Gran Guerra fue un acontecimiento que significó el fin del discurso civilizatorio que comenzó desde el siglo XVIII; del individuo y la libertad se pasó al conjunto de masas y a la muerte generalizada. La tecnología se destinó a facilitar el ejercicio de la muerte, más muertos en menos tiempo, y una despersonalización del enemigo. La muerte se siente cercana, en campos y ciudades, y no sólo quienes están en el campo de honor la padecen. Miriam Jerade nos cuenta que: "Freud ve en la guerra una involución de las pulsiones primitivas a partir de un contacto más cercano con la muerte que no se deja ya negar, de modo que la cultura intenta obliterar una relación con la muerte que se ha vuelto más directa, cuestión que produce una regresión a un estadio primitivo." 24

Varios investigadores se han preguntado sobre el carácter violento del hombre, algunos de ellos han llegado a la conclusión de que la violencia se encuentra inmersa dentro de su universo individual y colectivo y que, además, puede llegar a servir de elemento socializante y necesario para desarrollarse como ser integral. Freud, en un intercambio de correspondencia durante 1932 con el físico alemán Albert Einstein, reflexionó alrededor del tema de la guerra. En una de sus cartas, escrita en Viena en septiembre de ese año, Freud le plantea, fundamentalmente, que así como en el reino animal se acude siempre a la fuerza para resolver los conflictos, el hombre no se puede excluir de esta lógica. Además, teniendo como contexto histórico el periodo de entreguerras y, por ende, todo lo que tuvo de triste y doloroso para las gentes de las naciones europeas los hechos de la Primera Guerra Mundial, sumado a la búsqueda de la paz mundial a través de la creación de la Sociedad de las Naciones desde junio de 1919, llega a deducir que: "aunque parezca paradójico la guerra bien podía ser un recurso apropiado para establecer la anhelada paz eterna." ${ }^{25}$ Con todo lo que significó la Gran Guerra, durante la que se llegó a creer que iba a ser "la guerra que iba a acabar con todas las

23 Mario Elkin Ramírez Ortiz. Psicoanalistas en el frente de batalla. Las neurosis de guerra en la Primera Guerra Mundial. Medellín: Universidad de Antioquia, 2007, pág. I.

24 Miriam Jerade. "La guerra en Freud. Entre la hipersofisticación y una violencia arcaica", en: Revista Pléyade. No. 9, enero-junio 2012, pág. 24.

25 Sigmund Freud. "El porqué de la guerra", en: Obras Completas. Vol. XXII, Buenos Aires: Amorrortu editores, 1979, págs. I87-198. 
guerras". Las reflexiones de Freud se dirigían a que el hombre posee un instinto natural de la muerte y que es necesario canalizarlo. Por esta misma corriente, los etólogos, como Konrad Lorenz, relacionan más este impulso con la animalidad sin control, hablando así del instinto de supervivencia que el hombre posee como un animal como cualquier otro, sin dar, de hecho, respuestas a las expresiones violentas de la humanidad ${ }^{26}$.

De la misma manera, los sociólogos se han preocupado por comprender el fenómeno de la violencia. Algunos de ellos dicen que ella hace parte de las expresiones individuales dentro de la acción colectiva (Tilly); que el monopolio de la violencia legítima lo tiene el Estado y es él quien la ejerce y la debe controlar, donde hay violencia no hay un verdadero control estatal (Weber); que toda cultura tolera un cierto tipo de violencia, y algunas conductas violentas son legítimas para la sociedad (Haltung); o que la violencia es lo contrario del conflicto, es la ruptura completa, la separación, la violencia cierra toda posibilidad de conflicto (Lewis Coser ${ }^{27}$ y Wieviorka), esta última nos permite incluso diferenciar entre conflicto y lo que este último estudioso ha definido como "violencia expresiva".

En este sentido, Parsons fue el primero en trabajar las nociones de acción instrumental y acción expresiva dentro de las discusiones sobre la violencia. La primera tiene como características: un punto de vista discursivo, asociado a un pensamiento claro, una doctrina o una ideología, y una organización metódica conforme a la búsqueda de un fin concreto. Por el contrario, la segunda: llega a ser irracional, busca expresarse de cualquier manera, es inestable, y se puede producir rápidamente ${ }^{28}$. Las dos se manifestaron frecuentemente durante la Primera Guerra Mundial, y las ejecutaron los combatientes de cualquiera de los bandos en conflicto.

La mayoría de quienes participaron en los hechos de muerte de esta guerra no estaban preparados para el ejercicio de la violencia; en ella participaron todos aquellos que se enlistaron por amor a su patria y para combatir a un enemigo nacional. Panaderos, maestros de escuela, estudiantes, profesionales y demás, se convirtieron en víctimas y en victimarios potenciales. La muerte acechaba día y noche, y el enemigo no daba tiempo para pensar en la cotidianidad perdida. Las órdenes venían de sus superiores y se dirigían exclusivamente a matar. Para darle una explicación a estos fenómenos, nos serviremos de la noción de "Sumisión a la autoridad" de Stanley Milgram, quien, dentro de sus investigaciones sobre la violencia, le encargó a cierto número de sus estudiantes que les aplicaran choques eléctricos a un grupo de sus compañeros. En realidad, no había corriente eléctrica; pero las víctimas, que habían sido advertidas secretamente, debían lanzar gritos cada vez más horribles a medida que la intensidad de la corriente aumentaba, hasta llegar al desmayo. Obedeciendo incondicionalmente a su maestro, los estudiantes, que hacían las veces de victimarios,

26 Tomado de: Konrad Lorenz. "Lucha ritualizada", citado en: Fernando Gaitán Daza. "Una indagación sobre las causas de la violencia en Colombia", en: Malcolm Deas y Fernando Gaitán Daza. Dos ensayos especulativos sobre la violencia en Colombia. Bogotá: Fonade, Departamento Nacional de Planeación, 1995, pág. 97.

27 Lewis Coser. Las funciones del conflicto social. Buenos Aires: Fondo de Cultura Económica, 1961.

28 Ver: Michel Wieviorka. La Violence. París: Fayard, 
llegaron hasta el final de la última orden que se les dio29. Así actuaron la mayoría de los soldados que participaron en este gran conflicto.

A pesar de que dentro del grupo de combatientes algunos quizás rehusaban el hecho de matar, como lo cuentan los testimonios, había otros que se convirtieron en asesinos más eficaces, que parecían insensibles y, a veces, hasta entusiastas. Cada vez que el número de víctimas aumentaba, su sensibilidad parecía perderse, recobraban el apetito poco a poco, y su trabajo se convirtió en otro cualquiera; después de la primera muerte, las siguientes se hicieron mucho más fáciles de realizar.

La idea de que la guerra sería el motor de la historia, y como aquella que iba a terminar con los conflictos a futuro se fue desdibujando con el tiempo. Como lo reseña Miriam Jerade, citando un escrito de Walter Benjamin de 1936, quien escribió sobre un soldado que volvía enmudecido del campo de batalla: "Este enmudecimiento se refiere a una falla en la experiencia; los soldados volvían sin la posibilidad de comunicar porque algo en la guerra había sobrepasado la posibilidad de dar testimonio de lo vivido. La Primera Guerra Mundial impulsó una revolución tanto en la economía, en lo material, en las nociones éticas e, inclusive, en las vivencias del cuerpo, pero queda la duda sobre qué era lo que le impedía al soldado narrar su experiencia. [...] Una generación que todavía había ido a la escuela en tranvía tirado por caballos, se encontró súbitamente a la intemperie, en un paisaje en que nada había quedado incambiado a excepción de las nubes. Entre ellas, rodeado por un campo de fuerza de corrientes devastadoras y explosiones, se encontraba el minúsculo y quebradizo cuerpo humano." 30

Igualmente, Marc Crépon, filósofo francés, trata de explicar la violencia a través de lo que ha denominado: "el consentimiento asesino". Afirma que nosotros aceptamos la violencia así como nos oponemos a ella, y que nuestra relación con los demás está condicionada por la responsabilidad individual frente a los otros, pero que: "Con esta responsabilidad estamos confrontados a un principio ético que no cesaremos de trasgredir, sobre todo cuando nos comprometemos contra cualquier forma de violencia, inclusive aquellas insoportables, de una manera que implica el mismo recurso de la violencia. Esta transgresión, de la que nadie puede escapar, porque describe una dimensión inevitable de nuestra relación con el mundo, la he llamado recientemente: 'el consentimiento asesino'. Me tomó mucho tiempo llegar a darle un nombre a esta paradoja y llegar a la deconstrucción de todas las formas de invocación mortal de la pertenencia y de la identidad, todos los usos de la primera persona del plural, 'nosotros', siempre acompañada del 'ustedes', o del 'ellos' discriminante, son potencialmente mortales." 31

Crépon no aplica esta interpretación al caso de la Primera Guerra Mundial, pero, para nuestra investigación, podemos definir que, el discurso político y militar de la época direccionado hacia la muerte de un "ellos" extraño pero cercano, al que tenemos al pasar la frontera, hace que el "nosotros" se dedique exclusivamente al objetivo de la muerte. Además, por otro lado, no dejaremos de recalcar

29 Ver: Stanley Milgram. Obediencia a la autoridad: Un punto de vista experimental. Bilbao: Desclée de Brouwer, 1980.

30 Miriam Jerade, "La guerra en Freud. Entre la hipersofisticación y una violencia arcaica", Op.Cit., pág. 26.

31 Karl von Clausewitz. De la Guerra. Barcelona: Labor, 1992, pág. 218. 
que la Gran Guerra marcó un cambio en el pensamiento, si no mundial por lo menos sí occidental, en el que la muerte y todo lo alrededor de ella se vería de otro modo, lo que indudablemente se reflejó en todos los conflictos grandes o pequeños del siglo $X X$ y lo que llevamos del $X X \mid$.

\section{Conclusiones}

En todos los conflictos, desde la antigüedad hasta hoy en día, cualquier individuo que aparenta ser el más indefenso se puede convertir en un asesino sin piedad, y en alguien que es capaz de despedazar un cuerpo por razones ilógicas para nosotros, muy lógicas para él mismo. En las guerras siempre sobresalen instintos mortales ocultos en cada hombre, algunos de ellos innatos, otros tantos influenciados por creencias sociales o religiosas, o simplemente por las órdenes de un superior, en pocas palabras, por obligación. Durante una guerra se pueden presentar acciones incontroladas, ya que las armas y herramientas dan la fuerza para actuar de cara al enemigo, y éste, a su vez, reaccionará frente a su contrario de la misma forma o peor, hasta que se llega a una espiral mortal llena de sangre; como Clausewitz señalaba a propósito de los adversarios: "Ya no soy dueño de mí mismo, él fuerza mi mano como yo la suya" 32 . Además, el miedo a la muerte y a la forma en que ésta se va a encontrar rondaba de forma cotidiana el pensamiento de los combatientes de la Gran Guerra.

Igualmente, es necesario entender que la Primera Guerra Mundial no fue solamente un conflicto lejano y perdido en el tiempo, un enfrentamiento europeo que no tuvo consecuencias de impacto directo en los pobladores de Colombia a comienzo de siglo. No se trata tampoco de aprehender que los aspectos económicos y políticos del primer gran conflicto marcaron el inicio de un nuevo mapa geopolítico en América Latina, con los Estados Unidos como polo del mundo capitalista, o que la Revolución Bolchevique fortaleció el desarrollo del discurso obrero y campesino revolucionario en nuestros países. Esto es completamente válido, importante y necesario de comprender también. La muerte industrializada llegó durante estos años con toda su fuerza y señaló un cambio para los conflictos bélicos posteriores.

Con el presente escrito, quisimos plantear que este conflicto introdujo al hombre en una nueva época en la que la muerte, el "yo" y el "otro" ya no se verían de la misma forma. Esta modernidad de masas y de desarrollos nos fue alejando poco a poco de la muerte romántica, de la muerte familiar, en palabras de Philippe Ariès ${ }^{33}$. Las fosas comunes que dejó la peste negra en Europa se volvían a ver en el viejo continente a causa de la guerra. Enfermos físicos y mentales, mutilados, invidentes, viudas y huérfanos, deambulaban por las calles con rostros de dolor $y$, a veces, de desconsuelo y desilusión. Pero además, los conflictos del siglo XX, incluyendo al colombiano, de tantas décadas, fueron herederos de estas desgracias.

La máquinaria de la guerra, la industria armamentista, y en el campo de batalla armas cada vez más sofisticadas, alambrados, tanques, minas antipersonales y demás, fueron las herencias macabras que

32 Karl von Clausewitz. De la Guerra. Barcelona: Labor, 1992, pág. 218.

33 Philippe Ariès. Morir en occidente. Buenos Aires: Adriana Hidalgo Editora, 2000. 
nos dejó la Primera Guerra Mundial y, peor aún, fueron la antesala de la Segunda, con más víctimas, nuevos traumas, e incluso, un nuevo proyecto genocida. El monstruo de la muerte industrial llegó y se sigue llevando consigo a millones de individuos desde hace cien años.

\section{Bibliografía}

ALAIN. Souvenirs de guerre. París: Paul Hartmann Éditeur, 1937.

ARIÈS, Philippe. Morir en occidente. Buenos Aires: Adriana Hidalgo Editora, 2000.

CLAUSEWITZ, Karl von. De la Guerra. Barcelona: Labor, 1992.

COMISIÓN INVESTIGADORA DE LOS ATENTADOS ATRIBUIDOS A LOS ALEMANES. Informe acerca de los atentados atribuidos a los alemanes. Londres: Thomas Nelson, 1915.

COSER, Lewis. Las funciones del conflicto social. Buenos Aires: Fondo de Cultura Económica, 1961.

COURTEAULT, Paul. "Un conteur de guerre bordelais", en: Revue Philomathique de Bordeaux et du Sud-Ouest. 20e année, No. 6, novembre-décembre 1917, págs. 256-268.

CRÉPON, Marc. Le consentement meurtrier. París: Cerf, 2012.

DEAS, Malcolm y GAITÁN DAZA, Fernando. Dos ensayos especulativos sobre la violencia en Colombia. Bogotá: Fonade, Departamento Nacional de Planeación, 1995.

FREIRE, Héctor J. "Arte de la crueldad", en: Revista Topia. Buenos Aires, octubre 2003.

FREUD, Sigmund. Obras Completas. Buenos Aires: Amorrortu Editores, 1993.

JERADE, Miriam. "La guerra en Freud. Entre la hipersofisticación y una violencia arcaica", en: Revista Pléyade. No. 9, enero-junio 2012, págs. 23-35.

KÖPPEN, Edlef. Parte de Guerra. Barcelona: Sajalín editores, 2012.

MILGRAM, Stanley. Obediencia a la autoridad: Un punto de vista experimental. Bilbao: Desclée de Brouwer, 1980.

NOTHOMB, Pierre. Bélgica mártir. París: Parrin, 1915.

PILLET, Antoine. Les violences allemandes a l'econtre des non-combattants. París: Recueil Sirey, 1917.

RAMÍREZ ORTIZ, Mario Elkin. Psicoanalistas en el frente de batalla. Las neurosis de guerra en la Primera Guerra Mundial. Medellín: Universidad de Antioquia, 2007.

SONTANG, Susan. Sobre la fotografía. Barcelona: Edhasa, 1996.

TUFFRAU, Paul (Lieutenant E. R.). Carnet d'un combattant. París: Payot, 1917.

VALLOTTON, Benjamin. Au pays de la mort. París: Neuchatel Atttinger Fréres Editeurs, [s. f.].

WIEVIORKA, Michel. La Violence. París: Fayard, 2012. 